\title{
O RITMO E O GÊNERO
}

\author{
Olga Guerizoli Kempinska
}

(UFF)

Se o ritmo é uma noção que permite refletir de maneira instigante sobre as relações entre a poética, a estética e o gênero, é porque, através do ritmo, as oposições entre a natureza e a cultura, por um lado, e entre o indivíduo e a coletividade, por outro, adquirem bastante visibilidade, tornando-se, contudo, vulneráveis e suscetíveis de consideráveis deslocamentos e subversões. Projetado sobre a natureza e tido como responsável pela representação da correspondência entre o corpo humano e o universo, o ritmo é, na realidade, um produto da cultura. Descrito através de metáforas que, tal como a do coração ou a da respiração, remetem ao movimento dos órgãos, o ritmo não pode, no entanto, limitar-se à fisiologia do corpo biológico, sendo também uma forma de inscrição do indivíduo no domínio da vida coletiva e da história. Dificilmente situável nos extremos das oposições antropológicas e sociológicas - nós o produzimos e, igualmente, somos seus produtos o ritmo parece ter uma dupla vocação, estimulando tanto a participação quanto a resistência.

Neste artigo, composto de três partes, que seguem o movimento das principais oposições conceituais envolvidas na elaboração da reflexão moderna e contemporânea sobre o ritmo, tentarei discutir esse conceito, colocando-o em relação com o conceito de gênero. As tensões conceituais que estruturam este trabalho não são as únicas possíveis para se pensar o ritmo e, por exemplo, Henri Lefebvre propôs estruturar a reflexão sobre o ritmo em torno a oposições tais como a repetição e a diferença, 
o mecânico e o orgânico, a descoberta e a criação, o cíclico e o linear, o contínuo e o descontínuo, o quantitativo e o qualitativo (LEFEBVRE, 2004, p. 9). Assim, a escolha de me debruçar sobre o ritmo a partir das tensões entre o movimento das ondas e o fluxo do rio, entre a natureza e a cultura e entre a participação e a resistência, foi motivada sobretudo pelo envolvimento dessas oposições na reflexão sobre as relações entre a subjetividade, o corpo e o gênero. Os textos poéticos de Alfonsina Storni, Anna Akhmatova, Marianne Moore, Ingeborg Bachmann, Halina Poświatowska e Julia Hartwig, que põem o ritmo em prática e em questão de maneiras muito diversas, serão aqui lidos como importantes interlocutores dos textos teóricos de Iuri Tynianov, Óssip Mandelstam, Émile Benveniste, Henri Meschonnic e Julia Kristeva.

\section{Movimento das ondas ou fluxo do rio?}

O início do poema "Diante do mar", de 1919, de Alfonsina Storni, permite abordar a discussão do conceito de ritmo através da reflexão sobre uma de suas imagens mais afirmadas pela tradição. De fato, o texto traz uma analogia, considerada como uma representação "natural", entre o movimento das ondas do mar e o ritmo, desdobrada ainda em uma metáfora do movimento, fisiológico e emocional, do coração:

Ó mar, imenso mar, coração de fera

De ritmo irregular, coração mau,

Eu sou mais dócil que esse pobre pau

Que apodrece em suas ondas preso.

(...)

(STORNI, 1998, p. 84) ${ }^{1}$

No poema de Storni, a noção do ritmo permite estabelecer uma analogia entre o universo não humano, a subjetividade e o corpo. Uma novidade surge, no entanto, no segundo verso, o qual, desmentindo a ordem métrica da estrofe, afirma a falta de regularidade do ritmo, seu caráter bestial e a ambiguidade presente em sua relação com a disposição emocional do sujeito lírico, que se revela marcada não apenas pela permeabilidade, mas também pela corrupção.

Se a imagem das ondas do mar parece "natural" para expressar a ideia do ritmo enquanto articulação da relação entre o indivíduo, a natureza e

${ }^{1}$ Salvo indicação em contrário, as traduções propostas nesse texto são de minha autoria. 
o corpo, e se a expressão "ritmo irregular" presente no poema de Storni aproxima-se de um oxímoro, é porque o ritmo é frequentemente associado às noções de repetitividade e de regularidade. Assimilado aos esquemas métricos na poesia, rapidamente confundidos com as unidades naturais da respiração e com os movimentos cosmogônicos, "o ritmo insistente do mar ferindo a costa rochosa” foi também evocado para descrever o teor, ideal e inatingível, de uma narrativa épica enquanto o encontro rítmico, belamente anunciado pela imagem do reencontro de Penélope com Ulisses, entre o mito e o discurso, "no qual o sólido e inequívoco encontra-se com o fluido e o ambíguo, apenas para novamente se despedir" (ADORNO, 2003, pp. 47-48).

No entanto, antes de se ter tornado um elemento associado à repetição regular, evento que Émile Benveniste, em seu revelador artigo “A noção de 'ritmo' na sua expressão linguística”, de 1951, situa no pensamento de Platão, o ritmo relacionava-se sobretudo com a noção da forma dinâmica, remetendo à configuração espontânea ou improvisada de uma substância informe. Tratava-se da configuração de algo desprovido de uma consistência orgânica própria e determinada, por exemplo, da forma assumida momentaneamente pelas dobras de um tecido, ou pela forma que repentinamente tomava o humor.

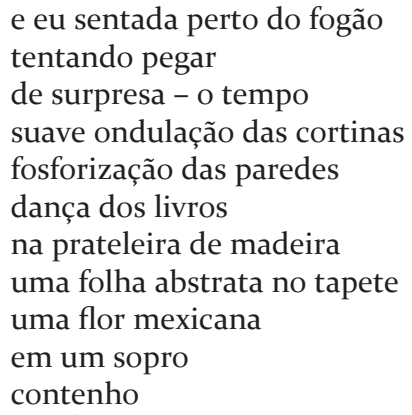

O poema de Halina Poświatowska, de 1968, com sua forma rítmica e visual que resiste à regularidade, descreve diversos exemplos de fenômenos que - tal como o tempo, o tecido solto, as impressões de luz e o ornamento - não possuem uma forma fixa, determinada e limitada. As tentativas de "pegar de surpresa" um tal fenômeno, de captá-lo e de contê-lo "em um sopro", instaurando uma relação fenomenológica entre o corpo, a percepção e o mundo, remetem aqui justamente à busca pelo ritmo. 
Em uma descrição poética das ondas, Paul Valéry captou maravilhosamente o caráter ilusório de sua regularidade e sua incessante transformação:

O vento listra a grande onda com pequenas ondas oblíquas. A pele da grande vaga fundamental fica arrugada regularmente por causa superficial da brisa, que levemente irrita a superfície; e a poderosa forma afluente de proveniência longínqua complica-se, torna-se uma massa com facetas, uma figura sólida cristalina em transformação incessante, donde emana o rumor de uma matéria em ebulição pela infinita quantidade de gritos íntimos, de rasgões e de amassaduras, de dobras e de misturas entre as águas. (VALÉRY, 2008, p. 311)

De fato, "fluir" é o sentido do verbo grego do qual deriva originalmente a palavra "ritmo". E o mar, apesar de ter sido tão frequentemente usado para a construção de imagens do ritmo, não flui - o que flui é, antes, o rio. Ao refletir sobre os usos da palavra "ritmo" em grego antigo, Benveniste ressaltou a ausência original da relação entre o ritmo e a regularidade, restaurando, assim, suas acepções semânticas mais abrangentes e, ao mesmo tempo, menos normativas: as de atribuição de forma, de configuração e de arranjo específico de partes. Benveniste insistiu sobretudo no caráter dinâmico do ritmo, mostrando que seu domínio era o da " forma no instante em que é assumida por aquilo que é movediço, móvel, fluido, a forma daquilo que não tem consistência orgânica" (BENVENISTE, 2005, p. 367). Maneira particular de fluir, o ritmo remetia originalmente a arranjos cronotópicos sujeitos a mudanças e não à fixidez do princípio do movimento regular e cadenciado.

Antes da reflexão etimológico-cultural de Benveniste, a relação entre o dinamismo da forma do texto literário e o ritmo já havia sido um dos problemas teóricos mais discutidos no âmbito do formalismo russo. Assim, Iuri Tynianov, no texto "O ritmo como fator construtivo do verso", de 1924, havia insistido no perigo de se imobilizar a forma poética, transformando-a em um mero recipiente do conteúdo: "na realidade, na noção de forma infalivelmente se insinua uma nota de estaticidade, estreitamente ligada à ideia do espaço (em vez disso, deveríamos conceber as formas espaciais como formas dinâmicas sui generis)" (TYNIANOV, 1983, p. 451). Esse dinamismo da forma, que abre o domínio da poética ao domínio da estética e da percepção não estática, é assegurado justamente pelo ritmo e encontra sua melhor expressão na imagem do fluxo.

Na mesma época em que Tynianov afirmava a importância do ritmo para a construção do discurso poético, o poeta Óssip Mandelstam debruçava-se sobre o alcance do ritmo na articulação da relação entre o 
indivíduo e a coletividade. Ao refletir, em 1920, no texto "O estado e o ritmo", sobre os efeitos da introdução da rítmica no programa escolar, o poeta via no ritmo um remédio eficaz contra a ameaça da constituição de um coletivismo sem coletividade, que, ao contrário da massa, é forçosamente constituída por indivíduos: "Nessas festas veremos uma nova geração ritmicamente educada, que expressará livremente seus desejos, suas alegrias e suas tristezas" (MANDELSTAM, 1994, p. 80). Apesar de seu tom panfletário, visível, por exemplo, na postulação de uma síntese do espírito e do corpo, o texto de Mandelstam insiste no caráter duplamente articulador do ritmo, que, responsável pela qualidade da energia social, participa da configuração tanto do indivíduo, suscetível de uma livre expressão, quanto da relação desse indivíduo com a coletividade.

Com efeito, tanto na ênfase dada à importância de se interpretar a construção poética como um "fluxo dinâmico" (TYNIANOV, 1983, p. 452) quanto no deslocamento da noção do ritmo do âmbito quantitativo para o âmbito qualitativo, está em jogo a oposição entre a dinâmica do fluxo e a estase da repetição. Debruçar-se sobre essa contradição, expressa em imagens concorrentes do ritmo - movimento das ondas do mar e movimento da corrente do rio -, que nos coloca perante a oposição entre a espontaneidade e a ordem, abre um caminho interessante para a reflexão sobre os usos que foram feitos do conceito do ritmo na história social da cultura.

\section{Natureza ou cultura?}

No poema intitulado "A criação", de 1936, Anna Akhmatova descreve o surgimento do ritmo justamente como a atribuição de uma forma a um caos sonoro. Precedido pelo aparecimento de barulhos cadenciados, que passam pelo processo de antropomorfização, o ritmo é instaurado a partir do levantamento de uma coluna de som, que passa a articular seu contraste com o silêncio. E é apenas após esse arranjo rítmico, pré-linguístico e operado não sem violência - expressa no movimento vertical que rompe a horizontalidade das sonoridades amorfas -, transformado em uma forma de ordenação dos princípios vitais e letais, que surge a linguagem. As palavras emergem primeiro como sonoridades, depois como sentidos:

Acontece deste modo: uma certa languidez;

No ouvido não se calam as pancadas dos relógios;

Ao longe diminui o estrondo do trovão. 
E vislumbram-se queixas e gemidos

De aprisionadas vozes que não se reconhecem.

Um certo círculo secreto estreita-se,

Mas nesse abismo de badaladas e murmúrios

Levanta-se um som que tudo venceu.

É tal o silêncio irreparável em seu redor

Que se escuta como no bosque cresce a erva,

Como anda pela terra o mal com seu alforje...

Mas as palavras começaram já a ouvir-se

E das rimas leves os tinidos de sinalização, -

É quando eu começo a compreender,

E de modo simples as linhas ditadas

Deitam-se no caderno branco de neve.

(AKHMATOVA, 2003, p. 35)

Articulação dinâmica do tempo e do espaço, forma do movimento, o ritmo torna-se a própria configuração da subjetividade no discurso segundo a teoria de Henri Meschonnic, formulada, em 1982, no livro Critique du rythme. Anthropologie historique du langage. "Se o sentido é uma atividade do sujeito, se o ritmo é uma organização do sentido no discurso, o ritmo é obrigatoriamente uma organização ou configuração do sujeito em seu discurso" (MESCHONNIC, 1982, p. 71), nota Meschonnic, vendo no ritmo o principal elemento antropológico da linguagem. Dinâmica e aberta, a inscrição do sujeito no discurso, que remete à sua organização poética, não pode deixar de desnudar o caráter político, socio-histórico e, com isso, genérico da própria subjetividade.

Mas se, por um lado, o ritmo, ao ser descrito como uma configuração dinâmica da subjetividade, revestiu-se na teoria de Meschonnic de uma importância antropológica capital, por outro, permaneceu praticamente indiferente à questão do gênero. E se muitas das oposições fundamentadas pela tradição, tais como, por exemplo, entre a poesia e a prosa, a poética da criação e a estética da recepção, ou ainda aquela entre a escrita e a oralidade, encontram-se desestabilizadas pela noção do ritmo meschonniquiano, a oposição entre o masculino e o feminino é aí evocada apenas de forma negativa, para colocar em questão a teoria do ritmo formulada por Julia Kristeva.

Para Kristeva, cuja tentativa de relacionar o corpo, o inconsciente, o sentido e o ritmo no livro La révolution du langage poétique, de 1974, foi chamada por Meschonnic, através do arcaísmo francês "ruineuse" (MESCHONNIC, 1982, p. 666), de, ao mesmo tempo, desestabilizadora e desestabilizada, o ritmo é um elemento crucial do domínio do semiótico. Fazendo parte da chora, pré-linguística e constituída pelos movimentos do corpo e pelas pulsões, o ritmo é capaz de subverter o domínio do 
simbólico responsável pela produção do sentido: "a chora, enquanto ruptura e articulação - ritmo - precede a evidência, o verossímil, o espaço e a temporalidade. Nosso discurso - o discurso - caminha contra ela, o que quer dizer que, ao mesmo tempo, nela se apóia e a rejeita" (KRISTEVA, 1974, p. 23). O ritmo, que ao mesmo tempo possibilita e ameaça o sentido - "repetição em ritmo e em canto, logo naquilo que ainda não é ou não é mais 'sentido”" (KRISTEVA, 198o, p. 36) - graças a sua participação na subversão dos processos de produção do sentido, encontra-se deslocado para o centro da revolução da linguagem poética.

Meschonnic entrevê na teoria kristeviana do ritmo, continuada no livro Pouvoirs de l'horreur Essai sur l'abjection, de 1980, o perigo de se instaurar "um novo avatar do dualismo do signo - o paradigma feminino/ masculino, que coloca o feminino do lado do significante e do ritmo, o masculino do lado do significado, e da teoria" (MESCHONNIC, 1982, p. 685). De fato, na teoria de Kristeva, e também na de Hélène Cixous, o ritmo enquanto uma estratégia do feminino, que remonta à autoridade arcaica materna - "minha mãe alemã na boca, na laringe, me ritma" (CIXOUS, 1986b, p. 31) -, se torna uma estratégia da natureza.

No entanto, a própria formulação da simplificação, sem dúvida criticável, que coloca o ritmo do lado da natureza, logo, do lado do feminino, revela-se aqui sintomática. A cultura, ou seja, o sistema gerador de símbolos, permite transcender a natureza e, nesse sentido, aparece como superior a esta. Desdobrada da oposição entre o doméstico e o público, a oposição entre a natureza e a cultura, amplamente afirmada no âmbito da antropologia, aproxima a mulher, com seu papel de mãe, de educadora de crianças e de preparadora de refeições, do domínio da natureza. No contexto dessa oposição, submetida hoje em dia a um exame cuidadoso por parte da antropologia feminista, a personalidade feminina estaria propensa a se autodefinir de acordo com sua "conectividade com os outros" e, dotada de "limites do ego mais flexíveis" (CHODOROW, 1974, p. 44), remeteria, de fato, a uma existência menos transcendente com relação à natureza.

A reflexão crítica em torno à oposição entre a natureza e a cultura é, no âmbito da presente discussão, particularmente importante na medida em que toca, ao mesmo tempo, o problema do ritmo e o problema do gênero. Com efeito, uma das primeiras a usar, ainda no início dos anos 70, o conceito do gender no sentido contraposto ao do sexo biológico, a socióloga inglesa Ann Oakley, em uma passagem famosa e até hoje amplamente citada, proveniente do livro Sex, Gender and Society, definiu o sexo como aquilo que diz respeito a "diferenças biológicas entre o macho e a fêmea, aquelas visíveis nos órgãos genitais e relacionadas às 
funções reprodutivas" (OAKLEY, 1972, p. 16). Ao passo que o conceito do sexo remete à dimensão fisiológica e natural do ser humano, o gender é situado por Oakley no domínio da cultura, relacionando-se à construção socio-histórica da identidade e à "classificação social em 'masculino' e 'feminino”" (OAKLEY, 1972, p. 16). O caráter interdisciplinar da discussão posterior acerca do alcance do conceito do gênero (cf. ŁEBKOWSKA, 2002) e, sobretudo, quanto ao papel central que nesse debate até hoje desempenha a oposição entre a natureza e a cultura, parece, de fato, aproximá-lo da discussão acerca do ritmo. Ambas as noções não apenas tornam a tensão entre a natureza e a cultura particularmente sensível, mas apontam também para uma série de desdobramentos, tais como a tensão entre o sujeito e a linguagem, entre o sujeito e o corpo, e, finalmente, entre o sujeito individual e a esfera coletiva.

Além disso, a reflexão sobre o ritmo tem em comum com a reflexão sobre o gênero o intuito de operar um deslocamento conceitual que vai do domínio da natureza para o domínio da cultura. Assim, um dos objetivos do artigo basilar de Benveniste consistiu no desmentimento da visão do ritmo associada à natureza, com seu movimento de ondas, e em sua colocação dentro do domínio da história e da cultura: "nada foi menos 'natural' que essa elaboração lenta, pelo esforço dos pensadores, de uma noção que nos parece tão necessariamente inerente às formas articuladas do movimento" (BENVENISTE, 2005, p. 370). Na continuação desse deslocamento conceitual, também Meschonnic insistirá no caráter sociocultural do ritmo: "O ritmo é comum à linguagem e ao corpo. Cada um dos três é social. Mauss mostrou que as técnicas do corpo são sociais, até o próprio fisiológico, dormir, andar, nadar, dar à luz, respirar, morrer, nada é natural.” (MESCHONNIC, 1982, p. 651) Mas, o muito citado por Meschonnic, Marcel Mauss, no texto "A noção de técnica do corpo", de 1934, havia sublinhado, de fato, não apenas a dimensão cultural da disposição física do ser humano, mas também a permanência da separação cultural dos sexos, quando diz que "há uma sociedade dos homens e uma sociedade das mulheres" (MAUSS, 2003, p. 409). A observação do processo da educação física dos dois sexos revela, de fato, que, longe de ser "natural", o comportamento do corpo é ao mesmo tempo socialmente adquirido e determinado pela distinção genérica.

Helmuth Plessner complicou essa visão da relação entre o ser humano e seu corpo, insistindo em sua duplicidade intrínseca, segundo a qual o ser humano, ao mesmo tempo, é existência física, ou seja, é carne (ist Leib) e tem a posse dessa existência na forma do corpo (hat diesen Leib als diesen Körper). No texto "Das Verhältnis des Menschen zu seinem Körper”, de 1941 (cf. PLESSNER, 2003), que faz parte da antropologia do 
riso e do choro como expressões-limite da natureza humana, Plessner debruçou-se sobre a duplicidade da relação entre o ser humano e seu corpo, expressa na ambiguidade da existência vivida como corpo-carne (als Körperleib) e no corpo-carne (im Körperleib). Aquilo que Mauss chama de "técnicas do corpo" parece corresponder em Plessner à noção do corpo, ou seja, ao aspecto da existência fisiológica experimentada como tida sob domínio, que possibilita a existência enquanto "carne dentro do corpo" (Leib im Körper) e, com isso, a vida dentro da sociedade.

Resulta disso que, da mesma maneira que há duas sociedades, a masculina e a feminina, responsáveis por dois sistemas de técnicas do corpo e por duas formas de se experimentar enquanto carne dentro do corpo, haveria também dois ritmos específicos e distintos. Como captar essa diferença rítmica? Seria realmente cabível definir o ritmo enquanto uma componente feminina do discurso, ou, ainda, formular uma teoria do "ritmo feminino", tal como Hélène Cixous no texto "O riso da Medusa" descreveu a "écriture féminine" (cf. CIXOUS, 1986a)? Antes de optar por esses caminhos teóricos, que, ambos, correm o risco de abraçar o essencialismo e de imobilizar o conceito do ritmo, transformando-o em uma noção normativa, paradigmática e a-histórica, parece-me mais produtivo insistir em seu aspecto articulador e na analogia que este aspecto encontra no lugar intermediário atribuído pela cultura à mulher. Marcado, segundo o discurso da cultura, pela tarefa de transformar o "cru" no "cozido", o feminino aparece, de fato, como um espaço de intenso entrecruzamento entre a natureza e a cultura: "O corpo humano, e ainda mais dramaticamente o corpo de uma mulher, é um estranho cruzamento entre zoè e bios, fisiologia e narração, genética e biografia" (CLÉMENT, KRISTEVA, 2001, p. 22).

\section{Participação ou resistência?}

Carregada de "uma maior ambiguidade simbólica" (ORTNER, 1974, p. 85) e, com isso, capaz de representar, por exemplo, tanto a vida quanto a morte, a mulher, tal como interpretada pela cultura, aparece como menos individualista do que o homem e, ao mesmo tempo, como intermediária entre o domínio da natureza e o domínio da cultura. A reflexão sobre as consequências dessa colocação simbólica - que combina um ego mais solto e mais disponível com a tarefa da mediação - para o ritmo revela que, no feminino, a capacidade da articulação rítmica é marcada pela ambivalência. 
É do individualismo que depende a qualidade da articulação rítmica. "Quando queremos formar uma sociedade, levando-a do caos para uma ordem harmoniosa do ser orgânico, esquecemos frequentemente, que, em primeiro lugar, é preciso formar a personalidade" (MANDELSTAM, 1994, p. 77). Ora, devido à configuração mais fraca do ego feminino, responsável pelo enfraquecimento do individualismo, do qual, segundo Mandelstam, retomado por Meschonnic, depende a qualidade da articulação rítmica entre o indivíduo e a coletividade, - pois “o ser humano amorfo e informe, a personalidade não formada é o maior inimigo da coletividade" (MANDELSTAM, 1994, p. 77) -, a atividade rítmica sofreria a partir da perspectiva feminina um considerável enfraquecimento. De fato, a valorização da conectividade com os outros apontaria muito mais para um "fluir com" do que para uma "forma particular de fluir".

Mas, ao mesmo tempo, a posição intermediária que o feminino ocuparia na oposição entre a natureza e a cultura, o lugar de passagem, no qual a forma é atribuída à substância amorfa, parece ser o lugar rítmico por excelência. A tensão instaurada entre essa potência posicional, paradoxalmente acompanhada de uma impotência pessoal, está muito presente na poesia escrita por mulheres e permite, a meu ver, colocar em questão a dimensão pragmática do ritmo. Uma pergunta importante acerca do ritmo diz, de fato, respeito a seus efeitos. O que o ritmo faz? Ele unifica ou, ao contrário, separa? Seria verdade que ele segura junto o mundo inteiro, relacionando o movimento dos corpos celestes, da natureza, com o movimento do corpo e do espírito humano e estendendo-se ainda às ações coletivas e aos fenômenos sociais? Ou, ao contrário, o ritmo, sendo o princípio subjetivo, asseguraria a possibilidade da separação de cada indivíduo?

A tensão entre o desejo de "fluir com" e o desejo de afirmar uma "forma particular de fluir" é, por exemplo, perceptível no poema "Uma água-viva”, de 1959, de Marianne Moore, na expressão da alternação entre a aproximação e a resistência da matéria incerta:

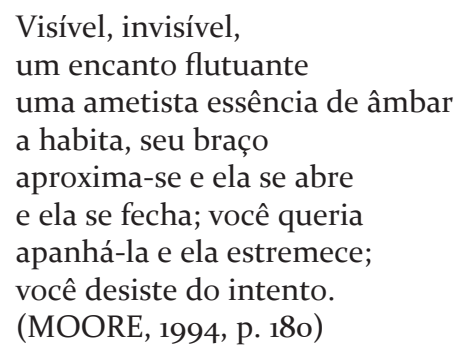

A palpitação rítmica da forma da água-viva, encenada pela forma visual do poema que, ao utilizar a disposição centralizada, insiste 
na simetria da pulsação gráfica dos versos, tem como seu motivo a instabilidade de sua configuração material, que oscila entreo aparecimento e o desaparecimento, entre a abertura e o fechamento. Essa oscilação provoca, por sua vez, a incerteza da possibilidade do contato entre o ser humano e a realidade não humana, levando ao movimento hesitante da aproximação e do distanciamento. A renúncia final à tentativa de captar a forma trêmula da água-viva, que se apresenta como uma renúncia à violência, afirma o ritmo enquanto uma forma de resistência.

A indecisão quanto à forma do envolvimento rítmico do ser humano na relação com o mundo aparece também em um poema sem título, de 1968, de Halina Poświatowska:

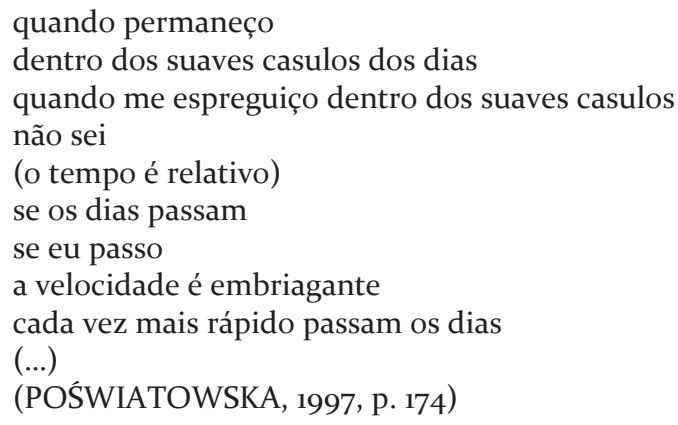

No poema de Poświatowska, é a relação entre a subjetividade e o tempo que está colocada em questão através da suspeita em torno de sua tradução topográfica em imagens animais e pré-natais de "casulos". A indecisão instala-se em torno da articulação entre o fluxo do tempo e o fluxo do "eu" - entre "fluir com o tempo" e "fluir no tempo".

No poema de Julia Hartwig intitulado "Segredos", de 2011, a incerteza quanto aos efeitos da correspondência rítmica está deslocada para a relação entre o ser humano e o mundo moral:

\footnotetext{
Há tantas coisas para elogiarmos quantas para nos queixarmos pois não faz parte da ordem das coisas que tudo seja medido e repartido devidamente Não será que existimos pelo que nos distingue e graças à coragem de nos distinguirmos Não se deixe colocar um carimbo Escute a música à parte para você foi escrita e reze à parte se puder E mesmo que tua tristeza seja contínua como um pulôver desfeito dia após dia chegará um momento em que te sentirás livre Olhe como as pessoas passam ao largo
} 
apesar de terem sido feitas umas para as outras

Ninguém é amado o suficiente e nem ama o suficiente

Eu olhava e via

mas só às vezes conseguia achar o nome daquilo

A verdade é o maior dos segredos

aos quais não temos acesso

(HARTWIG, 2011, p. 22)

"Oddzielnie" - advérbio proveniente do verbo "oddzielic", que significa em polonês "separar" - é a palavra usada no poema de Hartwig nos versos que contêm a injunção relacionada à maneira de escutar a música e de rezar, duas atividades humanas intimamente unidas com a ideia do ritmo. Pois é na música e na prece que, através da colocação em relação do corpo, da cosmogonia e da coletividade, as tensões entre a união e a separação e entre o domínio individual e o coletivo encontram sua maior intensidade. E "à parte", expressão que transpõe bem o advérbio "oddzielnie", não significa simplesmente "sozinho", remetendo, antes, à dinâmica da elaboração da distância, que, no entanto, não anula simplesmente a relação com a coletividade. A própria "ordem das coisas", descrita no poema como regida pela desmedida e pela lógica do desencontro e como aparentemente adversa e desprovida de harmonia, revela-se, misteriosamente, uma oportunidade para a liberdade. Nesse sentido, o ritmo aparece não como um movimento de confluir, nem como a ordem quantitativa prescrita pelo "carimbo", mas, antes, como uma negociação de autonomia do sujeito em relação com a realidade.

Um desassossego quanto ao potencial uniformizante do ritmo participativo deixa-se descobrir também no poema de Ingeborg Bachmann intitulado "Propaganda", de 1961:

Mas para onde vamos

calma fique calma

quando ficar escuro e quando ficar frio

fique calma

mas

com música

o que devemos fazer

alegre e com música

e pensar

alegre

a respeito de um certo fim

com música

e para onde levamos

de preferência

nossas perguntas e as tormentas de todos os anos

na lavanderia dos sonhos fique calma fique 
mas o que acontece

de preferência

quando o silêncio sepulcral

chega

(BACHMANN, 1961, p. 44)

"A cadência é a socialização máxima do ritmo: o slogan. A desindividualização máxima" (MESCHONNIC, 1982, p. 650). É a resistência a esse potencial ao mesmo tempo tranquilizador, alienante e totalizante do ritmo que encena o poema de Bachmann. Para além de uma simples irregularidade rítmica, a bivocalidade do poema instala um ritmo que consiste na própria quebra, gráfica e verbal, do fluxo discursivo. $\mathrm{O}$ discurso do questionamento existencial e o discurso calmante da propaganda, que faz da música e da repetição seus instrumentos, enfrentam-se no poema até o penúltimo verso, que instaura o silêncio.

Ao questionarmos a natureza e os efeitos do ritmo enquanto princípio da atribuição da forma dinâmica, resulta necessário deslocarmos a expressão "fazer algo em um ritmo", com seus desdobramentos tais como, por exemplo, "estar em um ritmo" ou "seguir um ritmo", para a expressão "fazer ritmo". Um tal deslocamento, que afirma um "fluir de uma forma particular" contra um simples "confluir" e contra uma submissão alienante do fluxo a uma ordem, ao devolver ao ritmo sua carga ativa, permite uma atualização de todas as tensões que o alimentam: entre o movimento das ondas e o fluxo do rio, entre a natureza e a cultura e entre a participação e a resistência. $\mathrm{O}$ ritmo do discurso poético, sendo o fator que, ao mesmo tempo, possibilita e ameaça a articulação e a configuração verbal, revela, com isso, seu princípio dinâmico, transformando-se em uma autêntica "tensão dinâmica". Em um movimento que combina a participação e a resistência, o discurso, o corpo e a intersubjetividade apoiam-se no ritmo e, ao mesmo tempo, contra ele caminham.

\section{REFERÊNCIAS BIBLIOGRÁFICAS}

ADORNO, Theodor W. Sobre a Ingenuidade Épica. In: Notas de literatura I. Trad. Jorge de Almeida. São Paulo: Duas Cidades: Ed. 34, 2003.AKHMATOVA, Anna. Poemas. Trad. Joaquim Manuel Magalhães, Vadim Dmitriev. Lisboa: Relógio d'Água, 2003. BACHMANN, Ingeborg. Anrufung des Grossen Bären. Gedichte. München: Piper, 1961.BENVENISTE, Émile. A noção de 'ritmo' na sua expressão linguística. In: Problemas de linguística geral I. Campinas: Pontes, 2005. 
126 - Remate de Males 34.1

CLÉMENT, Catherine, KRISTEVA, Julia. O feminino e o sagrado. Rio de Janeiro: Rocco, 2001.

CHODOROW, Nancy. Family Structure and Feminine Personality. In: ROSALDO, Michelle Zimbalist, LAMPHERE, Louise (org.). Woman, Culture, and Society. Stanford: Stanford University Press, 1974.

CIXOUS, Hélène. The Laugh of the Medusa. In: ADAMS, Hazard, SEARLE, Leroy (org.) Critical Theory since 1965. Tallahassee: University Press of Florida, 1986a. . Entre l'écriture. Paris: Des Femmes, 1986b.

DAVID-MÉNARD, Monique, DEUTSCHER, Penelope. Gender. In: CASSIN, Barbara (org.) Vocabulaire européen des philosophies. Paris: Seuil\&Le Robert, 2004. HARTWIG, Julia. Gorzkie żale. Kraków: Wydawnictwo a5, 2011.

KRISTEVA, Julia. La revolution du langage poétique. Paris: Seuil, 1974. . Pouvoirs de l'horreur. Essai sur l'abjection. Paris: Seuil, 1980.

LEFEBVRE, Henri. Rhythmanalysis. Space, Time and Everyday Life. London: Continuum, 2004.

ŁEBKOWSKA, Anna. Gender. In: MARKOWSKI, Michał Paweł. NYCZ, Ryszard (org.). Kulturowa Teoria Literatury. Główne problemy i pojęcia. Kraków: Universitas, 2002.

MANDELSTAM, Óssip. Staat und Rhythmus. In: Über den Gesprächspartner. Gesammelte Essays 1913-1924. Frankfurt: Fischer, 1994.

MAUSS, Marcel. Sociologia e antropologia. Trad. Paulo Neves. São Paulo: Cosac Naify, 2003.

MESCHONNIC, Henri. Critique du rythme. Anthropologie historique du langage. Paris: Verdier, 1982.

MOORE, Marianne. The Complete Poems of Marianne Moore. London: Faber and Faber, 1994 .

OAKLEY, Ann. Sex, Gender and Society. London: Temple Smith, 1972.

ORTNER, Sherry B. Is Female to Male as Nature Is to Culture?. In: ROSALDO, Michelle Zimbalist, LAMPHERE, Louise (org.). Woman, Culture, and Society. Stanford: Stanford University Press, 1974.PLESSNER, Helmuth. Ausdruck und menschliche Natur. Gesammelte Schriften VII. Frankfurt am Main: Suhrkamp, 2003. POŚWIATOWSKA, Halina. Właśnie kocham. Indeed I love. Kraków: Wydawnictwo Literackie, 1997.STORNI, Alfonsina. Antología poética. Buenos Aires: Editorial Losada, 1998.

TYNIANOV, Iuri. O ritmo como fator construtivo do verso. In: LIMA, Luiz Costa. Teoria da literatura em suas fontes. Vol. 1. Rio de Janeiro: Francisco Alves, 1983.

VALÉRY, Paul. Tel Quel. Paris: Gallimard, 2008. 